\title{
Intravascular Nodular Fasciitis
}

National Cancer Institute

\section{Source}

National Cancer Institute. Intravascular Nodular Fasciitis. NCI Thesaurus. Code C4729.

A rare self-limiting, rapidly growing, non-encapsulated benign neoplasm that arises from the vessels. It is characterized by the presence of plump spindle-shaped fibroblasts, multinucleated osteoclast-like giant cells, chronic inflammatory infiltrate, red blood cell extravasation, and high mitotic activity. 